\title{
Effect of Brine Water on Discharge of Cations in Membrane Capacitive Deionization and Its Implications on Nitrogen Recovery from Wastewater
}

David Inhyuk Kim ${ }^{\mathrm{a}, \mathrm{b}}$, Pema Dorji ${ }^{\mathrm{a}}$, Gimun Gwak ${ }^{\mathrm{b}}$, Sherub Phuntsho ${ }^{\mathrm{a}}$, Seungkwan Hong ${ }^{\mathrm{b}, *}$, and Hokyong Shon ${ }^{\mathrm{a}, *}$

${ }^{a}$ Centre for Technology in Water and Wastewater, School of Civil and Environmental Engineering, University of Technology, Sydney (UTS), Broadway, NSW 2007, Australia

${ }^{\mathrm{b}} \mathrm{School}$ of Civil, Environmental \& Architectural Engineering, Korea University, 145, Anam-ro, Seongbuk-Gu, Seoul, 02841, Republic of Korea

* Corresponding authors. E-mail addresses: hokyong.shon-1@uts.edu.au (H.K. Shon), skhong21@korea.ac.kr (S. Hong). 


\begin{abstract}
The ion desorption behavior from carbon electrodes onto high concentration brine was examined in this work because the ionic resources in brine are accumulated to attain high concentration in membrane capacitive deionization (MCDI) during mineral resource recovery. Several major issues were explored to demonstrate the suitability of MCDI for mineral recovery: ion discharge behavior using different solution chemistries $(0$ to $10 \mathrm{mM}$ of $\mathrm{NaCl}$, $\mathrm{KCl}$, and $\mathrm{MgCl}_{2}$ ) of feed and brine, desorption efficiencies of various electrode regeneration methods (reverse polarity, short-circuiting and power disconnection) for enrichment of ions, and ion desorption selectivity among selected cations ( $\mathrm{Na}, \mathrm{K}$, and $\mathrm{Mg}$ ). The desorption efficiency was inversely proportional to ionic strength of aqueous brine solution as the ions from electrodes migrate toward the brine solution against ionic-strength gradient. Furthermore, the desorption onto brine was constrained by utilizing energy-efficient short-circuiting, whereas the electrochemically adsorbed ions were well discharged by reversing the polarity compensating for its cost. The ions were preferentially released from the electrodes in order of $\mathrm{Na}>\mathrm{K}>\mathrm{Mg}$ in the results, showing a reverse trend with the selectivity of electrosorption. From ammonium recovery tests, a high concentration of ammonium in brine $(78.54 \mathrm{mg} / \mathrm{L})$ was obtained from the synthetic wastewater through continuous operation of five cycles, attributing to its selective desorption over sodium ions present. However, it must be noted that its incomplete discharge from the electrodes is a challenging issue to overcome the limitations of MCDI as a mineral recovery process, and to attain highly concentrated ammonium.
\end{abstract}

Keywords: Membrane capacitive deionization (MCDI); Electrosorption; Ion desorption; Resource recovery; Nitrogen recovery 


\section{Introduction}

As all the scarcity of fresh water, needs of mineral resources, and energy generation are the major issues facing the world, the paradigm of wastewater industry is in a time of transition today $[1,2]$. Aside from water purification and low energy consumption, a new role has been assigned to conventional wastewater treatment plants; mineral resource recovery, especially nutrients such as nitrogen and phosphorus led by the global trend. Wastewater is now considered as a potentially important source of recoverable nutrients and other valuable materials, and thus, resource recovery from wastewater has become a field where technological innovation is being developed for providing social, environmental and economic benefits [3]. The technologies recovering nitrogen and phosphorus from wastewaters, however, are still in progress of development as they are yet economically challenging [4, 5].

Capacitive deionization (CDI) has been known to have potential for deionization of saline water to harvest potable water through capturing charged impurities by applying electrical potential difference over two porous carbon electrodes. This electrosorptive technology has been one of the most promising and feasible technology especially for sustainable fresh water production from low saline unconventional water resources [6, 7]. Besides this process has been significantly improved by the researches on development of advanced materials of electrode, energy recovery, especially based on effective process designs, led this process be feasible for potable water production $[8,9]$. Aside from focusing on the generation of purified water, CDI also has a great potential for recovering mineral resources from water wastes [1025]. Using this technology, the charged species can be recovered by being adsorbed onto the electric double layers formed at the interface between an electrode and wastewater solution. As the electrosorption of CDI process roots in ion separation from water, it is effective for recovering the charged nutrient compounds by gathering the ions in minute amounts from a low salinity water.

Several studies that assessed the practical suitability of CDI for recovering mineral resources clarified that $\mathrm{CDI}$ can be a useful tool for mineral resource recovery attributing to its efficient ion separation from low salinity water and economic feasibility. Most earlier studies with CDI for mineral recovery carried basic tests to evaluate adsorption capacity and selectivity of target species. Especially, the works on CDI for reclamation of nitrogen [10-16] from municipal wastewaters have been only recently performed considering the nutrients as one of the most possibly renewable target. The ionic ammonium which is faradaically separable was 
shown to be stably stored in the pores of carbon electrodes by the non-faradaic electrochemical CDI process [10]. More than $65 \%$ of ammonium of recovery was attained by using a hybridized membrane CDI (MCDI) and ion exchange process with three successive operating cycles [11]. The ammonium concentration in the brine solution was concentrated up to $322 \mathrm{mg}-\mathrm{N} / \mathrm{L}$ via flow-electrode CDI allowing simultaneous removal and concentration of ammonia from the influent stream [12]. As the adsorption mechanisms in the CDI process has been widely studied, many solutions to optimize the performance and selectivity during nutrient recovery in CDI have been suggested. In the meanwhile, however, the behavior of ion discharge during the regeneration process has been barely investigated.

The main goal of this work is to understand the behavior of ion discharge in the regeneration stage of MCDI during mineral recovery, which is presently known as one of the most advanced CDI systems in this field [26]. The ions adsorbed onto the carbon electrode surface is discharged onto a high concentration brine for enrichment of mineral, the effect of brine concentration on ion desorption was investigated by changing the ionic compositions and strength of the synthetic feed and brine solutions. Besides the desorption efficiency of three different ion discharging methods (i.e., reverse polarity, short circuit and zero-voltage discharge) were evaluated during releasing the adsorbed ions onto brine. The selectivity of ion desorption was also studied using a mixture of different ions in the feed solution. The adsorption/desorption of MCDI was repeatedly run to attain high concentration of ammonium ions from a synthetic wastewater, and the improvement was discussed based on the findings through this study.

\section{Experimental}

2.1. Synthetic Na, K, and Mg solutions for desorption tests and synthetic wastewater feed for ammonium recovery tests

ACS graded sodium, potassium, and magnesium chlorides (Sigma-Aldrich, MO) were used as both feed and brine solutions for the experiments examining the ion discharge behavior under different ionic compositions (0.1-10.0 mM). A synthetic wastewater effluent was used during the tests of nitrogen recovery from municipal wastewater. The ionic composition of the synthetic feed solution was based on the water quality of the secondary effluent from selected wastewater treatment plants in California, USA (Table 1) [27]. The enriched synthetic 
wastewater was prepared by dissolving all ACS graded chemicals (Sigma-Alidrch, MO) in deionized (DI) water. Potassium phosphate and magnesium sulfate were replaced to potassium chloride and magnesium chloride, respectively, in order to prevent any possible scaling formation caused by the chemicals in the synthetic wastewater [28]. The total ionic strength of the modified synthetic wastewater was adjusted to be the same with that of the original wastewater. The organic matters originally contained in the wastewater were ruled out to ignore the effect of adsorption of negatively charged organics or possible fouling onto the carbon electrode surface.

Table 1. Chemical compositions of the synthetic wastewater solution as a feed solution.

\begin{tabular}{cccc}
\hline Constituent & $\begin{array}{c}\text { Molecular weight } \\
(\mathrm{g} / \mathrm{mol})\end{array}$ & $\begin{array}{c}\text { Concentration } \\
(\mathrm{mM})\end{array}$ \\
\hline \multirow{5}{*}{ Ionic } & Sodium citrate & 294.09 & 1.16 \\
composition & Ammonium chloride & 53.49 & 0.94 \\
& Potassium phosphate & 136.09 & 0.45 \\
& Calcium chloride & 147.01 & 0.5 \\
& Sodium bicarbonate & 84.01 & 0.5 \\
& Sodium chloride & 58.44 & 2.0 \\
& Magnesium sulfate & 246.47 & 0.6 \\
\hline
\end{tabular}

\subsection{Carbon electrodes and ion exchange membranes}

The symmetric two porous carbon electrodes used in this study were provided by Siontech Co. (Republic of Korea). The commercial carbon electrodes were composed of a graphite body sheet coated with a carbon slurry blended with activated carbon, P-60 (Kuraray Chemical Co., Japan) and PVDF (Inner Mongolia 3F-Wanhao Fluorin Chemical Co. Ltd., China). The dimensions of the carbon electrodes were $10 \times 10 \mathrm{~cm}^{2}$, and the consequent total carbon mass of each of them was $0.8 \mathrm{~g}$. Commercial anion and cation exchange membranes (Neosepta AFN and $\mathrm{CMB}$, respectively) purchased from Astom Corporation (Japan) have been used for inhibiting the adsorption of the counter-ions during electrode regeneration.

\subsection{Bench-scale MCDI setup}

The MCDI experiments were carried out in a lab-scale flow-through system as described in our previous work $[29,30]$. The dimensions of the rectangular feed channel of the test cell were $10 \mathrm{~cm} \mathrm{~W} \mathrm{x} 10 \mathrm{~cm} \mathrm{~L}$, and thus the effective electrosorption area was determined to be 100 $\mathrm{cm}^{2}$. Two carbon electrodes were symmetrically inserted within the test cell, and the 
anion/cation exchange membranes were placed between those two electrodes. The anion and cation exchange membranes were separated by a non-electrically conductive nylon spacer, ensuring the water flow and preventing short-circuit. The feed water was completely in contact with the carbon electrodes by punching a $1 \mathrm{~cm}$ diameter sized hole in the center of the carbon electrodes, ion exchange membranes, and nylon spacer [31].

A peristaltic pump (Cole-Palmer, IL) was placed to pump the feed solution throughout the MCDI system with a constant flow rate of $15 \mathrm{~mL} / \mathrm{min}$. A constant level of electrical potential was supplied through the MCDI unit by a potentiostat, WPG-100 (WonATech Co., Republic of Korea). More than 5 cycles of 2 min of electrosorption followed by $2 \mathrm{~min}$ of regeneration were repeated to stabilize the MCDI system under desired potential. After the stabilization, all the tests were performed in duplicate under room temperature.

\subsection{Experimental procedure for investigation of ion desorption behavior}

The experimental procedure for MCDI operation is presented in Fig. 1. The ions from a $100 \mathrm{~mL}$ feed solution containing $0.1,1.0$, or $10.0 \mathrm{mM}$ of $\mathrm{NaCl}, \mathrm{MgCl}_{2}$, or $\mathrm{KCl}$ was fed into the lab-scale MCDI system for $8 \mathrm{~min}$ at $1.0 \mathrm{~V}$ applied potential under batch mode. The ions adsorbed onto the carbon electrodes were then discharged under single-pass mode in the following regeneration step. In this step, the solution with 0 to $10 \mathrm{mM}$ of $\mathrm{NaCl}, \mathrm{MgCl}_{2}$, or $\mathrm{KCl}$ (named as brine solution used in the regeneration) was flowed through the system at $-1.0 \mathrm{~V}$ and $8 \mathrm{~min}$, and the concentrated water passed through the MCDI unit was collected in each min. After the experimental cycle was done, an additional regeneration stage was run with DI water to make sure all the ions are completely removed from the carbon electrodes. Thereby no further discharge of ions was detected by a conductivity meter ensuring that no ions are remained on the electrode surface that could be released by electrical force. A mixture of $\mathrm{NaCl}$, $\mathrm{MgCl}_{2}$, and $\mathrm{KCl}$ solutions (0 to $10 \mathrm{mM}$ in total) was also used for investigating the ion desorption behavior under co-existence of different ionic conditions.

\subsection{Successive five-cycle operation for concentrating ammonium}

A $100 \mathrm{~mL}$ portion of synthetic wastewater effluent was fed under batch mode through the MCDI system for $8 \mathrm{~min}$ at $0.9 \mathrm{~V}$ adsorption condition. The same volume of fresh DI water was prepared to circulate through the system at the same condition as electrosorption by reversing 
the potential. The desorbed ions including ammonium were kept collected onto the brine solution after regeneration for all cycles. This batch mode adsorption/desorption process was run for five cycles with $100 \mathrm{~mL}$ of fresh synthetic wastewater solution and $100 \mathrm{~mL}$ of concentrated brine solution for each test.
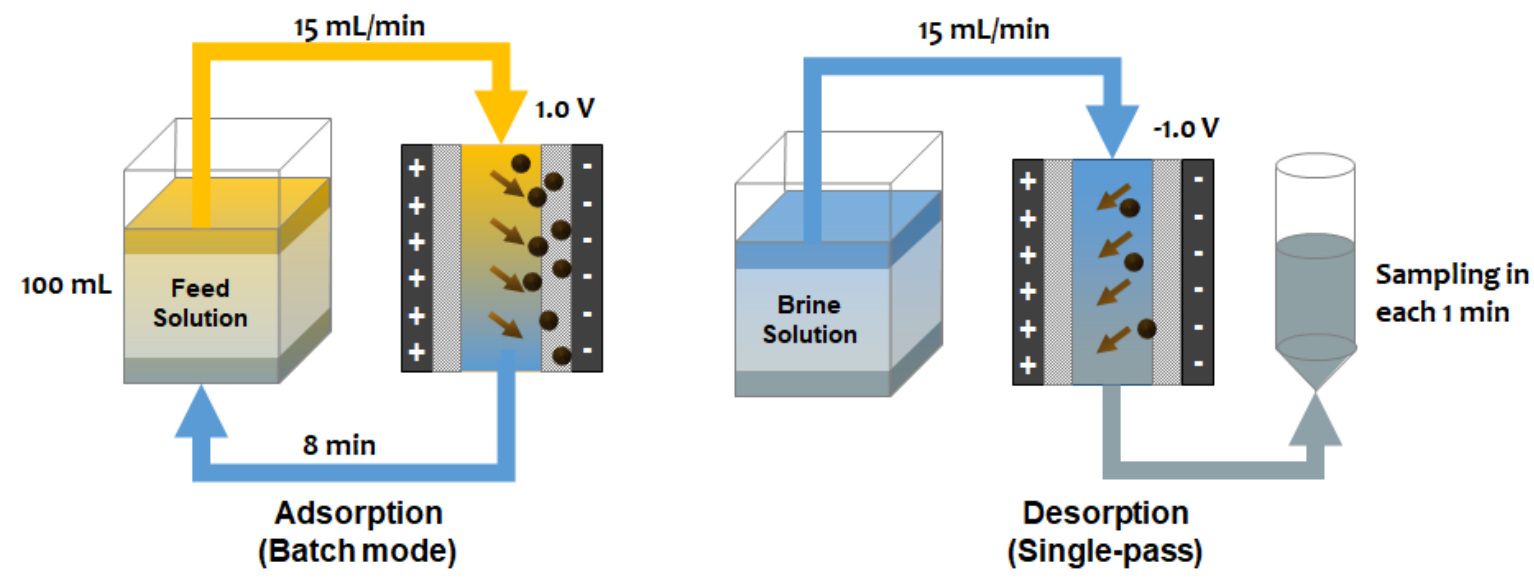

Figure 1. The experimental procedure of MCDI tests for investigation of the ion discharge onto high concentration brine solution

\subsection{Measurement of water quality}

The microwave plasma atomic emission spectrometry (MP-AES), (4100 MP-AES, Agilent Technologies, CA), was used to quantify the concentration of $\mathrm{Na}, \mathrm{Mg}$, and $\mathrm{K}$, whereas $\mathrm{NH}_{4}{ }^{+}$ was measured by a UV/VIS spectrophotometer (Spectroquant NOVA 60, Sigma-Aldrich, MO) using an ammonium photometric test kit (Merck Millipore, MA). The solution samples were diluted properly before analysis by the measurement devices. The calibration of MP-AES was carried out before measurement of samples by external calibration with deionized water and 5 standard $\mathrm{Na}, \mathrm{Mg}$, and $\mathrm{K}$ mixed solutions $(1.25,2.5,5,10,20 \mathrm{mg} / \mathrm{L}$ of each ion in the mixed solution).

The electrosorption removal efficiency from the feed solution after batch mode operation was calculated using Eq. (1):

Removal efficiency $(\%)=\frac{\left(C_{0}-C\right)}{C_{0}} \times 100$

where $\mathrm{C}_{0}$ and $\mathrm{C}(\mathrm{mg} / \mathrm{L})$ are the initial and final concentrations of feed, respectively. The salt 
desorption capacity with time, t, was calculated using Eq. (2):

Salt desorption capacity $(\mathrm{mg} / \mathrm{g})=\frac{m_{d, t}}{m}=\frac{Q \times \int_{0}^{t} \Delta C d t \times M}{m}$

Where $\mathrm{m}_{\mathrm{d}, \mathrm{t}}$ is the total amount of desorbed ions at $\mathrm{t}, \mathrm{Q}$ the volumetric flow rate $(\mathrm{ml} / \mathrm{min}), \Delta \mathrm{C}$ the molar concentration difference $(\mathrm{mM})$ between the influent and effluent at time $\mathrm{t}, \mathrm{M}$ the molar mass of salt ( $\mathrm{mg} / \mathrm{mmol})$, and $\mathrm{m}$ represents the total electrode mass used in the MCDI system. The desorption efficiency with t was calculated using Eq. (3):

Desorption efficiency $(\%)=\frac{m_{d, t}}{m_{a}} \times 100$

where $m_{a}$ represents the total mass of adsorbed salt in electrosorption step. The discharge selectivity of ion, i, at t can be expressed by Eq. (4):

Discharge selectivity of $\mathrm{i}=\frac{C_{i, t, b}}{C_{\text {total, }, b}}$

where $\mathrm{C}_{\mathrm{i}, \mathrm{t}, \mathrm{b}}$ means the molar concentration of $\mathrm{i}$ and $\mathrm{C}_{\text {total,t,b }}$ is the total molar concentration in the brine solution at $t$, respectively. The greater value of discharge selectivity implies the ion I is more preferentially discharged from the carbon electrode over other co-existing ions.

\section{Results and discussion}

\subsection{The behavior of ion discharge from the electrodes onto a brine with high ionic strength}

The target ions for recovery are to be highly enriched through successive CDI operational cycles in order to achieve a brine with high ion concentrations. To explore the effect of the ionic strength of the rinse solution on ion desorption during electrode regeneration, the CDI adsorption/desorption operation was carried out under various ionic compositions in the feed and rise solutions.

\subsubsection{Effect of the rinse solution concentration on ion desorption}

The desorption rate in MCDI was firstly evaluated using different $\mathrm{NaCl}$ feed and rinse solution concentrations to observe the effect of concentration difference at the interface between the carbon electrode surface and rinse solution, without the influence of other coexisting ions. Fig. 2 shows the desorption rate of MCDI in a single-pass mode operated under different $\mathrm{NaCl}$ feed concentrations (i.e., $0.1,1,10 \mathrm{mM}$ ) followed by desorption using different 
concentrations $(0,1,10 \mathrm{mM}$ of $\mathrm{NaCl})$ of rinse solutions. The desorption rate has been measured in terms of the $\mathrm{Na}^{+}$ions only for discussion. As expected, the ion desorption rate was high initially in the first minute of desorption time which then decreased as most of the $\mathrm{Na}^{+}$ions was released to the rinse water. The average initial desorption rate of electrode regeneration for electrodes operated with $0.1,1$, and $10 \mathrm{mM} \mathrm{NaCl}$ as feed solution were 5.6, 54.5, and 547.0 $\mathrm{mg} / \mathrm{L}-\mathrm{min}$, respectively when DI water was used as rinse water. However, when $1 \mathrm{mM} \mathrm{NaCl}$ solution was used as a rinse water, the initial desorption rate decreased to $3.5 \mathrm{mg} / \mathrm{L}$ for $0.1 \mathrm{mM}$ feed and $48.0 \mathrm{mg} / \mathrm{L}$ for $1.0 \mathrm{mM}$ feed. When a $10 \mathrm{mM} \mathrm{NaCl}$ solution was used as rinse water, the desorption rate further decreased to $0.2,29.1$ and $492.5 \mathrm{mg} / \mathrm{L}$ for electrodes operated with $0.1,1$ and $10 \mathrm{mM} \mathrm{NaCl}$ feed. The influence of the rinse water concentration on the decrease in the initial desorption rate was obviously more significant when the electrodes were operated at lower feed concentrations. For example, for electrodes operated with $0.1 \mathrm{mM}$ feed, the desorption rate decreased by $35 \%$ and $96 \%$ when $1 \mathrm{mM}$ and $10 \mathrm{mM}$ solutions were used as rinse water compared to DI rinse water. However, for electrodes operated with $1 \mathrm{mM}$ feed, the desorption rate decreased by only $13 \%$ and $47 \%$ when $1 \mathrm{mM}$ and $10 \mathrm{mM}$ solutions were used as rinse water compared to DI rinse water. For electrodes operated with $10 \mathrm{mM}$ feed, the desorption rate decreased by only $9 \%$ using $10 \mathrm{mM}$ rinse water compared to DI water rinse which is not very significant.

The main differences between the electrodes operated under three different feed concentrations presented in Figures 3(a), (b) and (c) are the mass of the ions adsorbed on the electrode surface. Electrodes operated with higher feed concentrations are expected to have correspondingly higher total mass of ions adsorbed on the electrodes as evident in the same Figure. Although the desorption rate generally decreased when a solution with higher concentrations is used as a rinse water, the results in Fig 3(c) are very promising because it shows that, the brine can be used with multiple times as rinse water for the successive desorption cycles thereby helping to have a high concentrated brine which is essential for enhancing the feed recovery rates and the recovery of resources from the more concentrated brine. When more concentrated rinse water is used, the decrease in the desorption rate can be explained due to the increased ionic concentration gradient between the electrode surface and the rinse water as elucidated by the Gouy-Chapman Theory [32]. Theoretically the electrical double-layer (EDL) capacity can be referred to determine the adsorption performance in CDI, which increases with the increase of electrolyte concentration in the feed water [33]. Oppositely, the high electrolyte concentration in the brine solution results in a low or reverse ion 
concentration gradient between the two phases (rinse water solution phase and carbon electrode surface), interrupting the ions being freed from the porous carbon surface. However this influence becomes less significant when the

Why the discharge rate is lower for Fig 2(a) compared to (b) and (c)? Is this because there was too much ions on the electrodes which is more easily removed by reversing polarity? How about the discharge efficiency in terms of the amount of ions desorbed to amount of adsorbed? Can this be calculated?
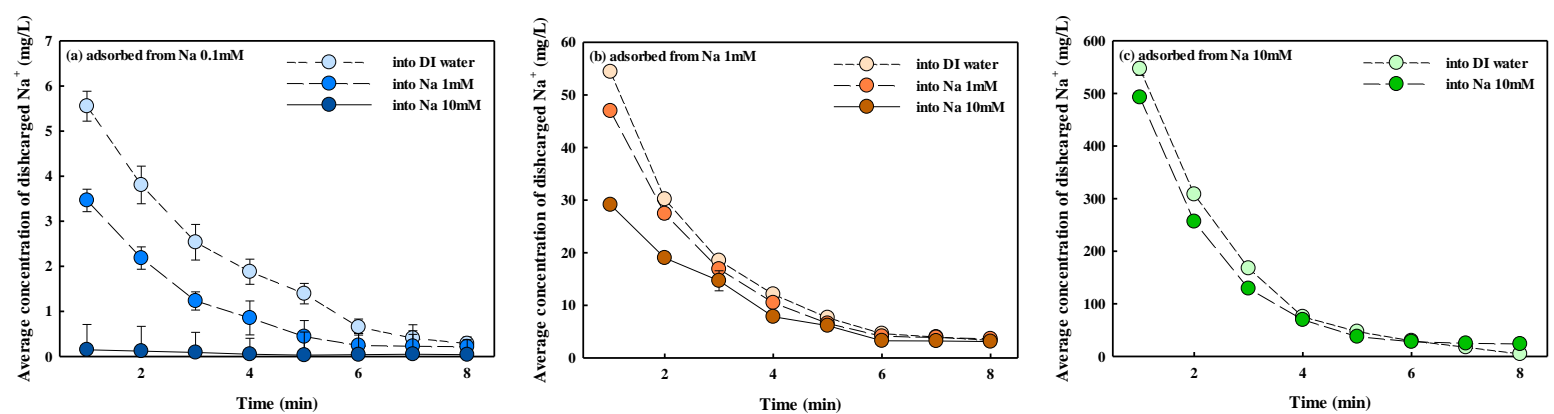

Figure 2. The average concentration of desorbed $\mathrm{Na}^{+}$onto brine solution ( 0 to $10 \mathrm{mM}$ of $\mathrm{NaCl}$ ). The samples were collected every min. The $\mathrm{Na}^{+}$ions were collected on the electrode from a $100 \mathrm{~mL}$ feed solution containing (a) 0.1 , (b) 1 , and (c) $10 \mathrm{mM}$ of $\mathrm{NaCl}$.

\subsubsection{Effect of the ion hydration size and charge valency of brine solution on ion desorption}

The $\mathrm{Na}^{+}$desorption performance of CDI using various types of rinse solution presented in Fig. 3 shows that the ion desorption efficiency was varied with the type of electrolyte used as desorbed water. The average $\mathrm{Na}^{+}$desorption rate in the early first minute was 47.0 and 29.1 $\mathrm{mg} / \mathrm{L}-\mathrm{min}$ as 1 and $10 \mathrm{mM}$ of $\mathrm{NaCl}$ were present in the brine, respectively. However, the average $\mathrm{Na}^{+}$desorption rate decreased when the brine solution was replaced with $\mathrm{KCl}$ or $\mathrm{MgCl}_{2}$ solutions. The initial average desorption rate of $\mathrm{Na}^{+}$ions that were adsorbed from the $1 \mathrm{mM}$ of $\mathrm{NaCl}$ feed solution reduced to 27.96 and 24.75 when disposed onto $10 \mathrm{mM}$ of $\mathrm{KCl}$ and $\mathrm{MgCl}_{2}$, in each. The desorption efficiency of $\mathrm{Na}^{+}$onto $\mathrm{KCl}$ brine was slightly lower than that of $\mathrm{NaCl}$, which may be considered insignificant. However, the $\mathrm{KCl}$ electrolyte still forms a stronger reverse ionic strength gradient as the ion activity becomes greater from the $\mathrm{K}^{+}$, ending up a 
lower ion desorption rate. A decrease in the desorption performance could be observed more clearly for $\mathrm{MgCl}_{2}$ brine which induced much higher ionic strength.
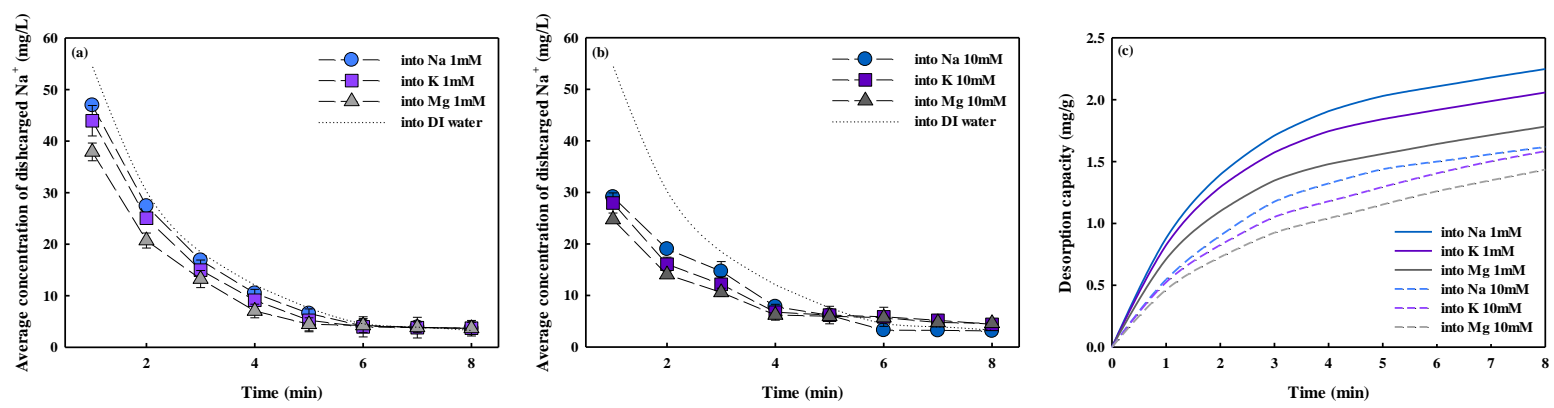

Figure 3. Average concentration of desorbed $\mathrm{Na}^{+}$onto brine solution ((a) $1 \mathrm{mM}$ and (b) $10 \mathrm{mM}$ of $\mathrm{NaCl}, \mathrm{KCl}$ or $\mathrm{MgCl}_{2}$ ) and (c) the corresponding desorption capacity of the used carbon electrode. The samples were collected every min. The $\mathrm{Na}^{+}$ions were collected on the electrode from a $100 \mathrm{~mL}$ feed solution containing $1 \mathrm{mM}$ of $\mathrm{NaCl}$.

Fig 3(c): Unit $\mathrm{mg} / \mathrm{g}$ ? what is the denominator $\mathrm{g}$ represent? Is it $\mathrm{mg}$ of feed ions adsorbed per $\mathrm{g}$ of what?

Based on the experimental observations above, the initial ion discharge efficiency decreases as the ionic concentration of the brine rinse solution becomes comparatively greater than the amount of ions adsorbed onto the carbon electrode surface. Besides, smaller hydration radius and higher valency of the ions in the aqueous brine solution lead to retarded ion desorption performance especially in the initial electrode regeneration stage. To sum up, the ionic strength gradient between the surface of the carbon electrode and the aqueous brine solution affects the ion discharge kinetics. The slowed desorption kinetics are consistent with the findings from earlier studies which probed the effect of brine composition on ion discharge in (M)CDI [30, $34]$.

There are lot of things to understand the real mechanisms involved in the desorption of adsorbed ions from the electrodes. The desorption efficiencies could also be different for each ionic species and also for different electrodes and IX membranes.

\subsection{Three different ion discharge methods for mineral resource recovery}

As discussed above, the efficiency of MCDI process for mineral resource recovery is 
concerned to be hampered by lowered ion desorption efficiency due to the intensified ion strength gradient. In recent years, short-circuiting has been acknowledged to be the most feasible electrode regeneration method during desalination of brackish water as no energy is required for ion discharge $[35,36]$. In this study, three different ion discharge methods were examined considering the lowered desorption efficiency caused by high concentration brine.
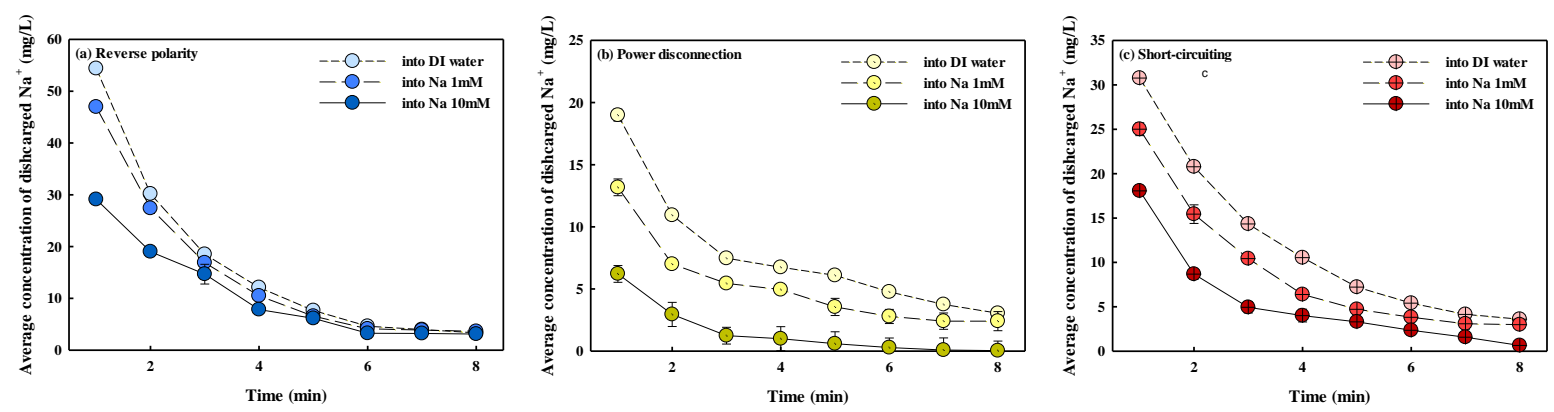

Figure 4. Effect of desorption methods on ions discharge performance in MCDI. The average concentration of desorbed $\mathrm{Na}^{+}$driven by (a) reverse polarity, (b) power disconnection and (c) short-circuiting.

Fig. 4 presents the discharged $\mathrm{Na}^{+}$concentration in three different ion discharge methods onto highly enriched brine solutions. The power disconnected electrodes exhibited the lowest desorption rate $(19.0 \mathrm{mg} / \mathrm{Lmin}$ in the first minute), and the initial desorption rate was significantly dropped by increasing $\mathrm{NaCl}$ concentration in brine (Fig. 4(b)). The ions were freed swifter under high brine concentration by short-circuiting (25.01 and $18.06 \mathrm{mg} / \mathrm{Lmin}$ under 1 and $10 \mathrm{mM}$ of $\mathrm{NaCl}$ in brine, respectively) as the electrostatic energy holding the ions were quickly dissipated, whereas the ions were slowly driven out from the carbon electrode when the power was disconnected (Fig. 4(c)) [34]. The ion desorption rate through reversing polarity was on top though the brine solution involved in high total dissolved solids. The ions were strongly expelled from the carbon electrode by electrostatic driving force (46.97 and 29.13 $\mathrm{mg} / \mathrm{Lmin}$ where $\mathrm{NaCl}$ at 1 and $10 \mathrm{mM}$ concentrations was used as brine, for each as shown in Fig. 4(a)).

The recent studies on CDI process demonstrated the energy-efficiency of short-circuiting as it requires no further electricity during electrode regeneration over the conventionally available polarity reversal which needs the same amount of energy that has been used for 
electrosorption. However, the results in our work suggest that short-circuiting is unlikely to be a proper choice for highly enriching the minerals, and reversing the polarity has better performance during mineral recovery compensating for its energy needs.

\subsection{Ion discharge from carbon electrodes under co-existence of different ions in feed solution}

\subsubsection{Competitive ion desorption among $\mathrm{Na}$, $\mathrm{K}$, and $\mathrm{Mg}$}

As different ions are present in wastewater together, electrode regeneration tests were carried out under a mixture of different ions in feed solution to understand the effect of coexisting ions on their migration from the carbon electrodes to the brine water. The experiments were performed using a feed solution with $0.33 \mathrm{mM}$ of $\mathrm{NaCl}, \mathrm{KCl}$, and $\mathrm{MgCl}$ for each. In the entire tests, the average removal efficiency of $\mathrm{Na}, \mathrm{K}$, and $\mathrm{Mg}$ from the feed solution was 71 , 96 and 97\%, respectively. Fig. 5(a) shows the desorption efficiency of the cations ( $\mathrm{Na}, \mathrm{K}, \mathrm{Mg}$ ) disposed onto DI water. In the beginning of the regeneration stage, $\mathrm{Na}$ was found to be the most preferably freed ion from the electrode surface, followed by $\mathrm{K}$, whereas $\mathrm{Mg}$ was the least favored species to be discharged. This trend can be clearly confirmed in Fig. 5(b), which presents the desorption percentage of the ions adsorbed on the cathode. The $\mathrm{Na}^{+}$ions took the shortest amount of time to be disposed among the three cations, while the longest time was needed to releaseall the adsorbed $\mathrm{Mg}$.
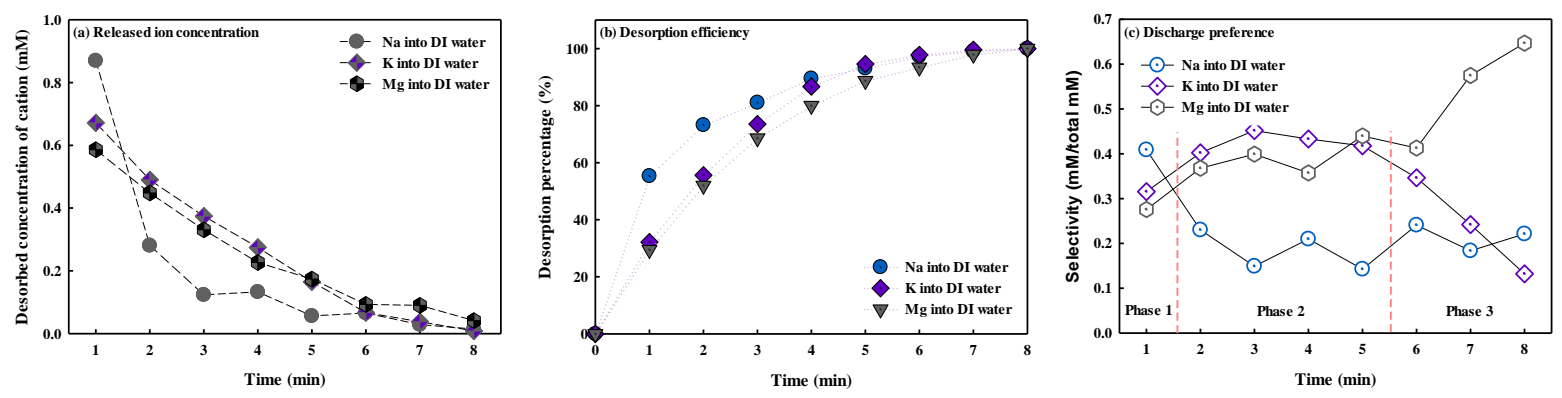

Figure 5. Competitive desorption among $\mathrm{Na}, \mathrm{K}$, and $\mathrm{Mg}$ ions. (a) The average concentration of desorbed, (b) desorption percentage, (c) and discharge selectivity of three different cations. The experiments were run using a mixed feed solution containing $0.33 \mathrm{mM}$ of $\mathrm{NaCl}, \mathrm{KCl}$, and $\mathrm{MgCl}_{2}$ for each. 
Several literatures that worked on competitive electrosorption reported that the electrosroption selectivity is firstly determined by initial concentration of feed, then ionic charge valency, and hydrated radius of ions [37,38]. First, the carbon electrodes preferentially hold the high concentration ions. In other words, the cations of higher valence are energetically more favorable to screen the surface charge of electrodes. So divalent charged species would be more electrochemically adsorbed on the electrode surface than monovalent ions if the concentrations of both are the same. With similar concentration, cations with smaller hydration radius show their size-affinity to approach to the pores. They are more favorably adsorbed by the electrostatic field.

From the given knowledge, the preferential ion sorption in this study has a sequence of $\mathrm{Mg}^{2+}>\mathrm{K}^{+}>\mathrm{Na}^{+}$. In contrast, the preferential order of ion discharge was revealed to be $\mathrm{Na}^{+}>$ $\mathrm{K}^{+}>\mathrm{Mg}^{2+}$, in which the trend was opposite to the electrosorption selectivity. The reversal trend between the competitive ion removal and preferential ion discharge implies that the ions preferentially adsorbed onto the carbon electrodes would be hardly released while the less competitively adsorbed ions would be discharged faster. The ion discharge selectivity could be divided into three phases (Fig. 5(c)). $\mathrm{Na}^{+}$was the first released species at the beginning of electrode regeneration due to its weak bonding with the carbon electrode surface. Later on, in the mid-stage after the majority of $\mathrm{Na}$ ions were disposed, $\mathrm{K}$ became the leading one being desorbed. Lastly Mg turned out to be the most preferentially desorbed ion in the end phase as it was the remaining species left on the electrode surface. Further tests were conducted investigating the discharge selectivity onto different concentrations of brine solution. The desorption rates of $\mathrm{Na}, \mathrm{K}$, and $\mathrm{Mg}$ were measured when those were disposed onto 1 and 10 $\mathrm{mM}$ brine solutions. Fig. 6 presenting the desorption selectivity in the first minute of electrode regeneration confirms that the trend of desorption preference was consistent regardless of the ionic strength of brine. 


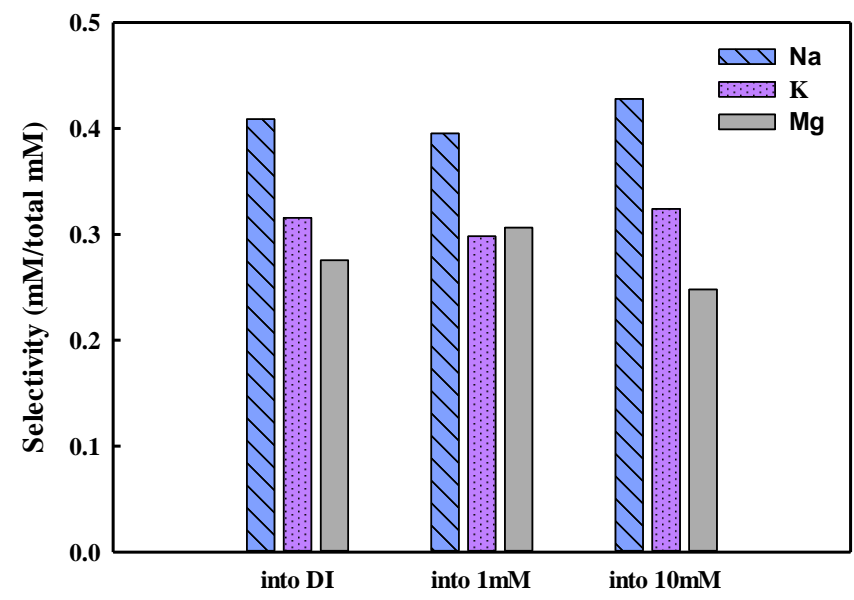

Figure 6. Discharge selectivity of $\mathrm{Na}, \mathrm{K}$, and $\mathrm{Mg}$ in the $1^{\text {st }}$ min of electrode regeneration. The ions were discharged onto 0,1 , and $10 \mathrm{mM} \mathrm{NaCl}$ brine solutions.

(반복실험을 하였나? error바가 필요함)

\subsubsection{Desorption kinetics using pseudo-first-order and pseudo-second-order models}

Several works on CDI evaluated the kinetics of electrosorption using pseudo-first and second order models [39-41]. Here in this study, kinetic models were also developed and executed to determine the preferential desorption among $\mathrm{Na}, \mathrm{K}$, and $\mathrm{Mg}$ ions. The desorption data was fitted using pseudo-first-order and pseudo-second-order kinetic models to provide numeric information from the kinetic constants.

The linearized pseudo-first-order and pseudo-second-order model equations can be described by Eq. (5) and (6).

$\log \left(q_{e}-q\right)=\log q_{e}-\frac{k_{1} t}{2.303} \quad$ for pseudo-first-order

$\frac{t}{q_{t}}=\frac{1}{k_{2} q_{e}{ }^{2}}+\frac{t}{q_{e}} \quad$ for pseudo-second-order

where $\mathrm{q}_{\mathrm{e}}$ and $\mathrm{q}_{\mathrm{t}}(\mathrm{mg} / \mathrm{g})$ are the adsorbed amount of salt and desorbed amount of salt at time $\mathrm{t}$ (min) during regeneration, respectively. $\mathrm{k}_{1}$ and $\mathrm{k}_{2}(\mathrm{~g} / \mathrm{mg}$-min) are the desorption rate constants of the pseudo-first and-second-order equations, respectively.

Fig. 7 shows the linear fitting between the model equations and experimental data. The desorption rate constants were obtained from the slopes and intercepts of the fitting lines and are listed in Table 2. Apparently both the first- and second-order models could approximate the 
experimental data. All the regression coefficients $\mathrm{R}^{2}$ for each fitting were more than 0.98 displaying compatible features. The order of $\mathrm{k}_{1}$ and $\mathrm{k}_{2}$ values for $\mathrm{Na}, \mathrm{K}$, and $\mathrm{Mg}$ were in good correspondence with the experimental results, indicating that the preferential desorption trend is $\mathrm{Na}>\mathrm{K}>\mathrm{Mg}$. However, the $\mathrm{q}_{\mathrm{e}}$ values estimated using the pseudo-second-order failed to accurately predict the results. The fitting results suggest that the pseudo kinetic models can be referred to quantitatively understand the behavior of ion desorption, as can be also observed in several previous studies on desorption kinetics [42-44].
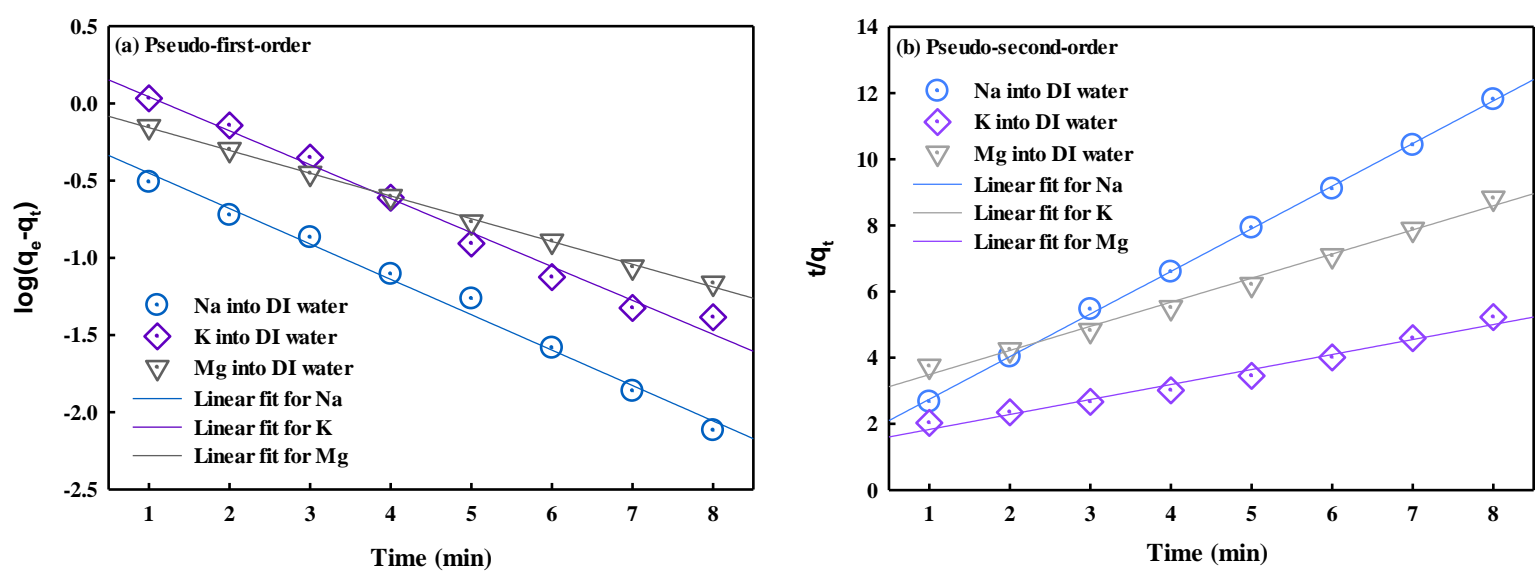

Figure 7. Linearized (a) pseudo-first-order and (b) pseudo-second-order kinetics fitting the results of discharged $\mathrm{Na}, \mathrm{K}$, and $\mathrm{Mg}$ ions.

Table 2. Parameters determined by fitting of pseudo-first-order and pseudo-second-order for the desorption performance.

\begin{tabular}{lllll}
\hline Kinetics & Parameter & \multicolumn{2}{l}{ Value } & $\mathrm{Mg}$ \\
\cline { 3 - 5 } & & $\mathrm{Na}$ & $\mathrm{K}$ & 0.9752 \\
\hline First-order & $\mathrm{q}_{\mathrm{e}}(\mathrm{mg} / \mathrm{g})$ & 0.6850 & 1.5722 & 0.3388 \\
& $\mathrm{k}_{1}(1 / \mathrm{h})$ & 0.5516 & 0.4793 & 0.9981 \\
& $\mathrm{R}^{2}$ & 0.9868 & 0.9831 & 1.3712 \\
Second-order & $\mathrm{q}_{\mathrm{e}}(\mathrm{mg} / \mathrm{g})$ & 0.7760 & 2.2080 & 0.2642 \\
& $\mathrm{k}_{2}(1 / \mathrm{h})$ & 0.8851 & 0.3285 & 0.9912 \\
\hline
\end{tabular}




\subsection{Recovery of $\mathrm{NH}_{4}^{+}$and discussions from observed desorption behaviors}

A synthetic wastewater effluent was fed through the MCDI system to recover $\mathrm{NH}_{4}{ }^{+}$. The removal and desorption efficiencies of the cations contained in the wastewater feed are listed in Table 3. The most competitively removed species was $\mathrm{Na}^{+}$followed by $\mathrm{NH}_{4}{ }^{+}$as those two hold the largest portion of cations in feed solution. $\mathrm{NH}_{4}{ }^{+}$was effectively collected $(89.68 \%$ removed) by the electrode under the employed operating conditions. The captured ions were then successively discharged onto a brine for several cycles to attain high concentration of $\mathrm{NH}_{4}{ }^{+}$. As presented in Fig. 8, the $\mathrm{NH}_{4}{ }^{+}$concentration in the brine solution showed a nearly linear increase after each cycle, and reached $70.70 \mathrm{mg} / \mathrm{L}$ after five cycle operation (4.17-fold compared to its initial concentration in the synthetic wastewater feed) suggesting that nitrogen resource in wastewater can be successfully reclaimed through MCDI. Theoretically, however, all the ammonium ions adsorbed onto the electrode in each cycle have to be fully desorbed and its concentration after five cycles was consequently supposed to be $76.04 \mathrm{mg} / \mathrm{L}$ assuming its fixed removal (89.68\%). This slightly lower amount of experimentally collected $\mathrm{NH}_{4}{ }^{+}$ions is likely due to the effect of ionic strength of brine on the desorption rate. In addition, the ratio of ammonium among all the cations in the solution increased by disposing the ions in the brine successively. From the discussions made earlier, the most competitively removed ions turn out to be reversely the least preferred species that is discharged from the electrode. In this regard, $\mathrm{Na}^{+}$was kept being less released, and thus its ratio in the brine solution became lower, whereas the other cations including $\mathrm{NH}_{4}{ }^{+}$were comparatively well discharged onto the brine solution. The results imply that ammonium ions can be well recovered by MCDI achieving high concentration with good selectivity. However, its incomplete discharge has to be improved for better nitrogen recovery from wastewater effluent.

Table 3. Ionic compositions of the feed and brine solutions after successive cycles operation.

\begin{tabular}{lllllll}
\hline Solution & & \multicolumn{2}{l}{ Constituent } & & & \\
& & $\mathrm{Na}^{+}$ & $\mathrm{NH}_{4}^{+}$ & $\mathrm{K}^{+}$ & $\mathrm{Ca}^{2+}$ & $\mathrm{Mg}^{2+}$ \\
\hline Feed & Concentration (mg/L) & 84.14 & 16.96 & 17.59 & 20.04 & 14.58 \\
Permeate & Removal (\%) & 69.32 & 89.68 & 89.76 & 90.14 & 89.68 \\
& SAC (mmol/g) & 0.317 & 0.105 & 0.050 & 0.056 & 0.067 \\
Brine & 1 cycle (mg/L) & 57.17 & 15.15 & 15.81 & 18.11 & 13.05 \\
& 3 cycle (mg/L) & 156.26 & 43.60 & 46.90 & 53.32 & 38.89 \\
& 5 cycle (mg/L) & 238.84 & 70.70 & 76.94 & 87.53 & 63.93 \\
& CF after 5 cycle & 2.84 & 4.17 & 4.37 & 4.36 & 4.38 \\
\hline
\end{tabular}




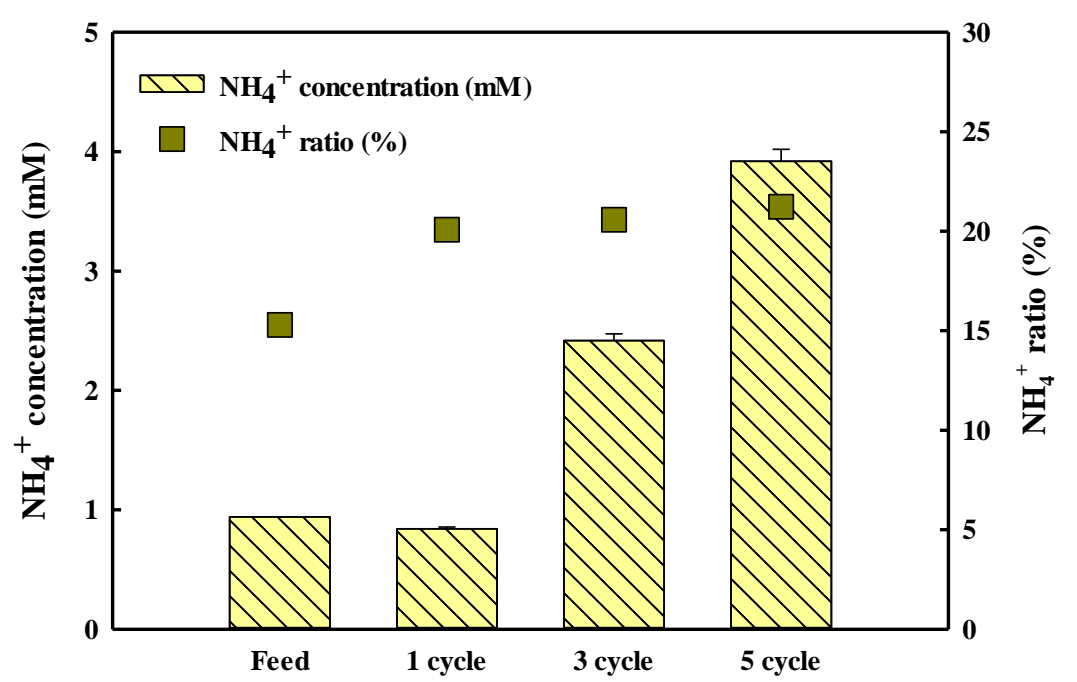

Figure 8. Concentration and ratio of $\mathrm{NH}_{4}{ }^{+}$in synthetic wastewater feed and brine solutions after 1,3 , and 5 cycle operation.

\section{Conclusions}

To understand the desorption behavior in MCDI for its use of mineral recovery, the migration of ions from carbon electrode toward high concentration brine has been explored in a lab-scale MCDI system under different ionic compositions of feed and brine solutions. The findings from this work were applied and utilized to elucidate the discharge of ammonium ions collected for wastewater effluent. The major outcomes from this study are summarized as below:

- The ionic strength gradient between carbon electrode surface and bulk brine solution greatly influences ion desorption efficiency. Stronger ionic strength of brine induced by higher concentration, higher ion valency, and smaller hydration radius retards the ion desorption rate.

- Energy-efficient regeneration methods such as short-circuiting and power disconnection are unlikely effective for highly concentrating the mineral resources due to its weak repulsive force. The electrochemically adsorbed ions are well discharged by applying reverse polarity compensating for its cost, and hence higher ion concentration of brine can be obtained. 
- The selective desorption experiments confirmed that the preferential sequence of ion discharge was $\mathrm{Na}^{+}>\mathrm{K}^{+}>\mathrm{Mg}^{2+}$, which is completely reverse to the electrosorption. The ions which are more competitively adsorbed onto the carbon electrode are hardly released.

- The ammonium ions can be substantially recovered by MCDI because of high removal from the wastewater effluent and stable discharge onto brine solution. However, its lowered desorption efficiency onto high concentration of brine may arouse concern of poor recovery performance and thus should be improved by establishing proper strategies such as applying higher energy potential during electrode regeneration.

Can you also mention the modelling results?

\section{Acknowledgement}

This work is supported by the Korea Agency for Infrastructure Technology Advancement (KAIA) grant funded by the Ministry of Land, Infrastructure and Transport (Grant 18IFIPB116952-03).

\section{References}

[1] P.L. McCarty, J. Bae, J. Kim, Domestic wastewater treatment as a net energy producer-can this be achieved?, in, ACS Publications, 2011.

[2] W. Mo, Q. Zhang, Energy-nutrients-water nexus: integrated resource recovery in municipal wastewater treatment plants, Journal of environmental management, 127 (2013) 255-267.

[3] R. Connor, A. Renata, C. Ortigara, E. Koncagül, S. Uhlenbrook, B.M. Lamizana-Diallo, S.M. Zadeh, M. Qadir, M. Kjellén, J. Sjödin, The United Nations World Water Development Report 2017. Wastewater: The Untapped Resource, The United Nations World Water Development Report, (2017).

[4] F. Volpin, L. Chekli, S. Phuntsho, J. Cho, N. Ghaffour, J.S. Vrouwenvelder, H.K. Shon, Simultaneous phosphorous and nitrogen recovery from source-separated urine: A novel application for fertiliser drawn forward osmosis, Chemosphere, 203 (2018) 482-489.

[5] D. Batstone, T. Hülsen, C. Mehta, J. Keller, Platforms for energy and nutrient recovery from domestic wastewater: A review, Chemosphere, 140 (2015) 2-11.

[6] R. Zhao, S. Porada, P. Biesheuvel, A. Van der Wal, Energy consumption in membrane capacitive deionization for different water recoveries and flow rates, and comparison with reverse osmosis, Desalination, 330 (2013) 35-41.

[7] S. Porada, R. Zhao, A. Van Der Wal, V. Presser, P. Biesheuvel, Review on the science and technology of water desalination by capacitive deionization, Progress in Materials Science, 58 (2013) 1388-1442.

[8] M. Suss, S. Porada, X. Sun, P. Biesheuvel, J. Yoon, V. Presser, Water desalination via capacitive deionization: what is it and what can we expect from it?, Energy \& Environmental 
Science, 8 (2015) 2296-2319.

[9] Y. Liu, C. Nie, X. Liu, X. Xu, Z. Sun, L. Pan, Review on carbon-based composite materials for capacitive deionization, Rsc Advances, 5 (2015) 15205-15225.

[10] Z. Ge, X. Chen, X. Huang, Z.J. Ren, Capacitive deionization for nutrient recovery from wastewater with disinfection capability, Environmental Science: Water Research \& Technology, 4 (2018) 33-39.

[11] Z. Wang, H. Gong, Y. Zhang, P. Liang, K. Wang, Nitrogen recovery from low-strength wastewater by combined membrane capacitive deionization (MCDI) and ion exchange (IE) process, Chemical Engineering Journal, 316 (2017) 1-6.

[12] K. Fang, H. Gong, W. He, F. Peng, C. He, K. Wang, Recovering ammonia from municipal wastewater by flow-electrode capacitive deionization, Chemical Engineering Journal, 348 (2018) 301-309.

[13] W. Tang, P. Kovalsky, D. He, T.D. Waite, Fluoride and nitrate removal from brackish groundwaters by batch-mode capacitive deionization, Water research, 84 (2015) 342-349.

[14] J.-H. Yeo, J.-H. Choi, Enhancement of nitrate removal from a solution of mixed nitrate, chloride and sulfate ions using a nitrate-selective carbon electrode, Desalination, 320 (2013) $10-16$.

[15] Y.-J. Kim, J.-H. Choi, Selective removal of nitrate ion using a novel composite carbon electrode in capacitive deionization, Water research, 46 (2012) 6033-6039.

[16] Y.-J. Kim, J.-H. Kim, J.-H. Choi, Selective removal of nitrate ions by controlling the applied current in membrane capacitive deionization (MCDI), Journal of membrane science, 429 (2013) 52-57.

[17] G.-H. Huang, T.-C. Chen, S.-F. Hsu, Y.-H. Huang, S.-H. Chuang, Capacitive deionization (CDI) for removal of phosphate from aqueous solution, Desalination and Water Treatment, 52 (2014) 759-765.

[18] C. Macías, P. Lavela, G. Rasines, M. Zafra, J. Tirado, C. Ania, Improved electro-assisted removal of phosphates and nitrates using mesoporous carbon aerogels with controlled porosity, Journal of Applied Electrochemistry, 44 (2014) 963-976.

[19] S.-Y. Huang, C.-S. Fan, C.-H. Hou, Electro-enhanced removal of copper ions from aqueous solutions by capacitive deionization, Journal of hazardous materials, 278 (2014) 8-15. [20] C.-C. Huang, J.-C. He, Electrosorptive removal of copper ions from wastewater by using ordered mesoporous carbon electrodes, Chemical engineering journal, 221 (2013) 469-475.

[21] T. Ryu, J.C. Ryu, J. Shin, D.H. Lee, Y.H. Kim, K.-S. Chung, Recovery of lithium by an electrostatic field-assisted desorption process, Industrial \& Engineering Chemistry Research, 52 (2013) 13738-13742.

[22] T. Ryu, D.-H. Lee, J.C. Ryu, J. Shin, K.-S. Chung, Y.H. Kim, Lithium recovery system using electrostatic field assistance, Hydrometallurgy, 151 (2015) 78-83.

[23] S. Kim, H. Yoon, D. Shin, J. Lee, J. Yoon, Electrochemical selective ion separation in capacitive deionization with sodium manganese oxide, Journal of Colloid and Interface Science, 506 (2017) 644-648.

[24] H. Wang, C. Na, Binder-free carbon nanotube electrode for electrochemical removal of chromium, ACS applied materials \& interfaces, 6 (2014) 20309-20316.

[25] L. Yang, Z. Shi, W. Yang, Enhanced capacitive deionization of lead ions using air-plasma treated carbon nanotube electrode, Surface and Coatings Technology, 251 (2014) 122-127.

[26] P. Biesheuvel, A. Van der Wal, Membrane capacitive deionization, Journal of Membrane Science, 346 (2010) 256-262.

[27] E. Huertas, M. Herzberg, G. Oron, M. Elimelech, Influence of biofouling on boron removal by nanofiltration and reverse osmosis membranes, Journal of Membrane Science, 318 (2008) 264-270. 
[28] D.I. Kim, J. Kim, S. Hong, Changing membrane orientation in pressure retarded osmosis for sustainable power generation with low fouling, Desalination, 389 (2016) 197-206.

[29] J. Choi, H. Lee, S. Hong, Capacitive deionization (CDI) integrated with monovalent cation selective membrane for producing divalent cation-rich solution, Desalination, 400 (2016) 3846.

[30] D. Kim, G. Gwak, P. Dorji, D. He, S. Phuntsho, S. Hong, H. Shon, Palladium recovery through membrane capacitive deionization (MCDI) from metal plating wastewater, ACS Sustainable Chemistry \& Engineering, (2017).

[31] J.-H. Lee, W.-S. Bae, J.-H. Choi, Electrode reactions and adsorption/desorption performance related to the applied potential in a capacitive deionization process, Desalination, 258 (2010) 159-163.

[32] P. Delahay, Double layer and electrode kinetics, John Wiley \& Sons Inc, 1965.

[33] M. Mossad, L. Zou, A study of the capacitive deionisation performance under various operational conditions, Journal of hazardous materials, 213 (2012) 491-497.

[34] Q. Yao, H.L. Tang, Effect of Desorption Methods on Electrode Regeneration Performance of Capacitive Deionization, Journal of Environmental Engineering, 143 (2017) 04017047.

[35] R. Zhao, P. Biesheuvel, A. Van der Wal, Energy consumption and constant current operation in membrane capacitive deionization, Energy \& Environmental Science, 5 (2012) 9520-9527.

[36] R. Zhao, O. Satpradit, H. Rijnaarts, P. Biesheuvel, A. Van der Wal, Optimization of salt adsorption rate in membrane capacitive deionization, Water research, 47 (2013) 1941-1952.

[37] C.-H. Hou, C.-Y. Huang, A comparative study of electrosorption selectivity of ions by activated carbon electrodes in capacitive deionization, Desalination, 314 (2013) 124-129.

[38] Z. Chen, H. Zhang, C. Wu, Y. Wang, W. Li, A study of electrosorption selectivity of anions by activated carbon electrodes in capacitive deionization, Desalination, 369 (2015) 46-50.

[39] Z. Chen, C. Song, X. Sun, H. Guo, G. Zhu, Kinetic and isotherm studies on the electrosorption of $\mathrm{NaCl}$ from aqueous solutions by activated carbon electrodes, Desalination, 267 (2011) 239-243.

[40] Y. Wimalasiri, M. Mossad, L. Zou, Thermodynamics and kinetics of adsorption of ammonium ions by graphene laminate electrodes in capacitive deionization, Desalination, 357 (2015) 178-188.

[41] R.L. Zornitta, L.A. Ruotolo, Simultaneous analysis of electrosorption capacity and kinetics for CDI desalination using different electrode configurations, Chemical Engineering Journal, 332 (2018) 33-41.

[42] D. Mahanta, G. Madras, S. Radhakrishnan, S. Patil, Adsorption and desorption kinetics of anionic dyes on doped polyaniline, The Journal of Physical Chemistry B, 113 (2009) 22932299.

[43] E. Njikam, S. Schiewer, Optimization and kinetic modeling of cadmium desorption from citrus peels: A process for biosorbent regeneration, Journal of Hazardous Materials, 213 (2012) 242-248.

[44] M. Hossain, H. Ngo, W. Guo, T. Setiadi, Adsorption and desorption of copper (II) ions onto garden grass, Bioresource Technology, 121 (2012) 386-395. 
